\title{
Statins in heart failure: do we need another trial?
}

\author{
This article was published in the following Dove Press journal: \\ Vascular Health and Risk Management \\ 14 June 2013 \\ Number of times this article has been viewed
}

\section{Kwadwo Osei Bonsu \\ Amudha Kadirvelu Daniel Diamond Reidpath \\ School of Medicine and Health Sciences, Monash University Sunway Campus, Bandar Sunway, Malaysia}

\begin{abstract}
Statins lower serum cholesterol and are employed for primary and secondary prevention of cardiovascular events. Clinical evidence from observational studies, retrospective data, and post hoc analyses of data from large statin trials in various cardiovascular conditions, as well as small scale randomized trials, suggest survival and other outcome benefits for heart failure. Two recent large randomized controlled trials, however, appear to suggest statins do not have beneficial effects in heart failure. In addition to lowering cholesterol, statins are believed to have many pleotropic effects which could possibly influence the pathophysiology of heart failure. Following the two large trials, evidence from recent studies appears to support the use of statins in heart failure. This review discusses the role of statins in the pathophysiology of heart failure, current evidence for statin use in heart failure, and suggests directions for future research.
\end{abstract}

Keywords: statins, treatment, heart failure, comorbidity, mortality

\section{Introduction}

Heart failure (HF) is a complex clinical syndrome which results from structural and functional disorders of the heart associated with a variety of cardiovascular diseases. HF is mainly characterized by a condition in which the heart cannot pump enough blood to the rest of the body. With an increasing number of patients, HF is becoming a major worldwide public health problem which requires a global response. In recent decades, significant strides have been made in the treatment of HF with the appearance of angiotensin-converting enzyme (ACE) inhibitors, angiotensin-II receptor blockers (ARB), $\beta$-blockers, aldosterone antagonists, and device therapies. ${ }^{1}$ However, mortality and morbidity is still high and further strategies are needed to avert or reduce adverse outcomes. 3-hydroxy-3-methylglutaryl coenzyme A (HMG-CoA) reductase inhibitors, commonly called statins, are one of the novel but affordable pharmacological agents that have been investigated in patients with HF in recent years.

Statins are a class of drugs that have become one of the most important lipid lowering medications with proven efficacy in treatment of hyperlipidemia. Lovastatin was the first statin introduced into clinical practice in 1987. Now there are seven different statins available for clinical use. Statins are grouped into two main categories according to their origin: (1) naturally occurring statins of fungal origin or semisynthetic analogs, such as lovastatin, pravastatin, and simvastatin; or (2) synthetic statins including fluvastatin, atorvastatin, rosuvastatin, and pitavastatin. ${ }^{2}$ Generally, statins are regarded as a remarkably safe and well-tolerated class of drugs, despite the withdrawal of cerivastatin in $2001 .^{3}$ Statins lower plasma cholesterol levels by competitive inhibition of the rate-
Correspondence: Amudha Kadirvelu School of Medicine and Health Sciences, Monash University Sunway Campus Jalan Lagoon Selatan, Bandar Sunway 46150 Selangor DE, Malaysia

Tel +60355146316

Fax +60355146323

Email amudha.kadirvelu@monash.edu submit your manuscript $\mid$ www. dovepress.com

Dovepress

http://dx.doi.org.//0.2147/VHRM.S44499
Vascular Health and Risk Management 2013:9 303-319

(C) 2013 Bonsu et al, publisher and licensee Dove Medical Press Ltd. This is an Open Access article which permits unrestricted noncommercial use, provided the original work is properly cited. 
determining enzyme HMG-CoA reductase in the mevalonate pathway. It is well-established that statins reduce morbidity and mortality in patients with coronary artery disease $(\mathrm{CAD})^{4,5}$ and prevent its progression to $\mathrm{HF}^{6}$ The mevalonate pathway also produces isoprenoids (farnesyl pyrophosphate and geranylgeranyl phosphate) as intermediates ${ }^{7}$ which mediate the activation of various signaling molecules via the prenylation of small guanosine triphosphate (GTP) binding proteins: Rho, Ras, and Rac. Rho is involved in the activation of inflammatory cytokines and the formation of the actin cytoskeleton which affects intracellular transport, messenger ribonucleic acid (mRNA) stability, and gene transcription. ${ }^{8,9}$ The Ras proteins regulate cell proliferation and hypertrophy, whereas Rac are involved in reactive oxygen species (ROS) generation via nicotinamide adenine dinucleotide phosphate (NADPH) oxidase activation. By inhibiting HMG-CoA reductase, statins decrease isoprenoid production and consequently downregulate Rho, Ras, and Rac mediated signaling pathways. ${ }^{7}$ In addition to lowering cholesterol, statins exert cholesterol-independent effects through mevalonate inhibition; these include the enhancement of endothelial function, reduction of neurohormonal activation, decrease in proinflammatory cytokines, and the attenuation of ventricular remodeling - all of which play a critical role in $\mathrm{HF}$ progression and prognosis.

Clinical evidence from observational studies and retrospective and post hoc analyses of data from randomized trials in various cardiovascular conditions suggest the survival benefit of statins for HF.,10-14 Statins appear to have many pleiotropic effects believed to influence the pathophysiology to confer survival and further outcome benefits in HF. Notwithstanding these observations, two large scale randomized trials - the Controlled Rosuvastatin Multinational Study in Heart failure (CORONA) ${ }^{15}$ and Gruppo Italiano per lo Studio della Sopravvivenza Nell'Insufficienza Cardiaca Heart Failure (GISSI-HF) ${ }^{16}$ - which randomized patients to one type of statin at a low dose (rosuvastatin $10 \mathrm{mg}$ ) or a matching placebo, did not show improved survival in patients with HF. Clinicians, therefore, withhold statins due to reports of potential harmful effects and lack of substantial clinical trial data to support their use in HF. ${ }^{17}$ Moreover, recent studies have not confirmed the detrimental effects of statins in HF reported in the CORONA and GISSI-HF trials. ${ }^{18,19}$ The lack of clarity surrounding the effect of statins in HF raises important clinical questions. This review discusses the role of statins in the pathophysiology of HF, current evidence for statin use in heart failure, as well as possible future research directions.

\section{Potential mechanisms for beneficial effects of statins in the pathophysiology of HF}

$\mathrm{HF}$ is a complex syndrome typified by hemodynamic and metabolic alterations, elevation of inflammatory and oxidative stress markers, endothelial dysfunction (ED), neurohormonal activation, plaque instability, and adverse cardiac remodeling. Statins show various favorable lipiddependent and lipid-independent effects which are believed to alter the pathophysiological mechanisms and may bring about clinical benefits in HF.

\section{Endothelial function}

The endothelium is a monolayer of cells lining the innermost surface of blood vessels; it serves as a functional and structural barrier between blood and the vessel wall to prevent platelet and leucocyte aggregation, control the permeability of plasma constituents, and regulate blood flow. The endothelium also regulates vascular tone through balanced production of vasodilators and vasoconstrictors in response to various stimuli. ${ }^{20}$ Endothelium produces nitric oxide (NO) - a prime mediator of normal vascular function which dilates smooth muscles and relaxes myofibrils in response to endogenous (bradykinin, acetylcholine, and catecholamines) and exogenous (ischemia, shear stress, and temperature changes) stimulation. ${ }^{21}$ The normal endothelium also provides antiinflammatory and antiproliferative actions, and modulates fibrinolysis and coagulation pathways to maintain the hemostatic properties of blood vessels. ${ }^{22} \mathrm{ED}$ is characterized by decreased NO bioavailability due to impaired NO production by the endothelium and/or increased NO inactivation by ROS. The after effect is impaired vasodilatation, increased vasoconstriction, platelet aggregation, cytokine release, smooth muscle cell proliferation, and increased oxidative stress. ${ }^{23} \mathrm{HF}$ severity is associated with NO imbalance and the ensuing ED. ${ }^{24}$ Decreased NO mediated vasodilation is common in ED, and appears to impair myocardial perfusion, reduce coronary blood flow, ${ }^{25}$ and worsen ventricular function in $\mathrm{HF}^{24} \mathrm{ED}$ also contributes to increased vascular stiffness and impairs the ability of arteries to distend, resulting in myocardial damage. ${ }^{26}$ Furthermore, NO imbalance in ED alters matrix metalloproteinase (MMP) which affects cell migration, cardiac hypertrophy, and atherosclerotic plaque stability. ${ }^{27}$ In HF, elevated levels of endothelin-1 (ET-1) a potent vasoconstrictor - cause increased vasoconstriction, matrix production, and smooth muscle cell growth to worsen endothelial function and accelerate HF progression. ${ }^{27}$ Reduced blood flow coupled with increased lactate 
production from NO downregulation-mediated catabolism of free fatty acids partly accounts for exercise intolerance seen in patients with $\mathrm{HF}^{28}$

Statins appear to induce NO synthetase (eNOS) - an enzyme which catalyzes the production of $\mathrm{NO}$ expression in human endothelial cells. ${ }^{29}$ Statins have been shown to prevent the expression of caveolin, which is a negative regulator of eNOS. ${ }^{30}$ Atorvastatin and simvastatin also inhibit ET-1 mRNA expression and reduce plasma levels of ET-1. ${ }^{31-33}$ The protein kinase Akt has been identified as a major regulator of cell growth, survival, ${ }^{34}$ and eNOS activity. Simvastatin induces Akt-mediated phosphorylation of eNOS, which gives rise to heightened NO production and endothelial cell survival. ${ }^{35}$ Thus, statins' modulation of Akt activity may partly explain improvement in endothelial function, enhanced tissue perfusion, and reduced cardiovascular events seen in treated patients. Statins further inhibit Rho activation to increase endothelial NO production. ${ }^{29}$ Experimental animal models confirm the beneficial effects of statins in ED; ${ }^{36,37}$ likewise, clinical studies have demonstrated improved endothelial function with high, optimal, and low doses of statins. $^{38-40}$

\section{Inflammation}

$\mathrm{HF}$ is characterized by worsened inflammation due to the activation of proinflammatory cytokines, cell adhesion molecules, endothelial cells, cardiac myocytes, ${ }^{41,42}$ the complement system, and cardiac autoantibodies, ${ }^{18}$ which are produced by activated macrophages. Elevated proinflammatory cytokines - tumor necrosis factor $\alpha$ (TNF- $\alpha$ ), interleukin (IL)-1, IL-6, IL-10, and C-reactive protein (CRP) - have been implicated in HF morbidity and mortality. ${ }^{41}$ These mediators are associated with left ventricular remodeling, enhanced cardiac myocyte apoptosis, ED, and incidence of anorexia and cachexia ${ }^{41,43}$ in HF. Statins reduce plasma concentrations of proinflammatory cytokines $^{44,45}$ and have been shown in in vitro mononuclear cell cultures of normal human subjects. ${ }^{46} \mathrm{~A}$ couple of in vitro studies suggest statins show anti-inflammatory properties through the inhibition of isoprenoid intermediates which serve as ligand attachments for intracellular signaling molecules in the mevalonate pathway. ${ }^{45,46}$ Statins ameliorate inflammation in HF by favorably modulating many signaling pathways which include endothelial NO synthase, tissue-type plasminogen activator, ET-1, and plasminogen activator inhibitor $\mathrm{I}^{33}$

Further, statins have been shown to reduce activation of the transcription factor $\mathrm{NF \kappa B},{ }^{47}$ which is associated with the production of acute-phase proteins such as angiotensinogen, adhesion molecules, and cytokines, ${ }^{48}$ and are all known to play an important role in the progression of HF.

\section{Myocardium remodeling}

Myocardial remodeling is a genomic expression that leads to cellular, molecular, and interstitial changes in the heart characterized by change in size, shape, and function. HF progression is closely associated with ventricular remodeling which manifests as myocyte hypertrophy and ventricular dilation. Angiotensin II mediated mechanisms via the angiotensin II type 1 (AT1) receptor stimulation downstream of the mevalonate pathway account for ventricular remodeling in $\mathrm{HF}^{7}$ Statins downregulate AT1 receptor mediated negative effects such as enhanced sympathetic activation, vasoconstriction, sodium retention, ROS formation, and cardiac hypertrophy, ${ }^{49}$ and thus prevent and/or attenuate myocardial remodeling.

Statins may also prevent remodeling via modulation of the effects of MMPs - protein-degrading enzymes involved in the breakdown and remodeling of tissues and organs including the myocardium. MMPs promote extracellular matrix degradation and remodeling whereas endogenous tissue inhibitors of MMP (TIMP) inhibit these effects.

An imbalance between activated MMP and TIMP promotes extracellular matrix degradation and myocardial remodeling in the development of HF. ${ }^{50}$ Myocardial MMP levels increase in dilated cardiomyopathy. ${ }^{51}$ Statins suppress expression of MMP-9, MMP-3, and MMP-1 while upregulating the expression of TIMP - a mechanism that could limit extracellular breakdown, ${ }^{52,53}$ thereby inhibiting myocardial fibrosis and remodeling.

Studies in human and animal models have confirmed that statins attenuate myocardial remodeling by reducing cardiac myocyte hypertrophy, activation of MMP, fibrosis, and myocardial cell apoptosis. ${ }^{54,55}$ A recent study reported that simvastatin inhibits TNF- $\alpha$ induced myofibroblast proliferation and MMP-9 secretion in a concentration dependent fashion in $\mathrm{HF} .{ }^{56}$ Statins also promote endothelial function and inhibit platelet activation ${ }^{57}$ to reduce ventricular remodeling after acute myocardial infarction in coronary artery ligation animal models, ${ }^{58}$ and these cardioprotective effects may be attributed to the statins' activation of the protein kinase Akt. The protein kinase Akt acts downstream of the mevalonate pathway to promote production of vascular endothelial growth factor and angiopoietin $^{59}$ that stimulate endothelial cell survival and promote angiogenesis. 
There is some evidence to suggest that statins promote regression of left ventricular mass in patients with angina pectoris $^{60}$ and produce antiarrhythmic effects in high-risk patients with HF through downregulation of potential unfavorable effects of AT1 receptor stimulation. Moreover, Krum et $a l^{61}$ showed that statin therapy has no effect on left ventricular remodeling in patients with New York Heart Association (NYHA) functional class II or III ischemic or nonischemic HF when randomized to either rosuvastatin $40 \mathrm{mg}$ or a placebo in addition to standard therapy for 6 months. The highest effective dose of rosuvastatin ( $40 \mathrm{mg}$ ) used achieved a remarkable $57 \%$ reduction in plasma low density lipoprotein (LDL) levels but failed to improve markers of cardiac remodeling. In another study, low dose statins exhibited enhanced endothelial cell proliferation, migration, and differentiation, but the effect was inhibited at high doses after acute coronary syndrome ${ }^{62}$ suggesting a biphasic effect requiring further investigations. Cerivastatin reduces collagen I and fibronectin deposition to prevent ventricular hypertrophy in a transgenic rat model and may ameliorate angiotensin II-induced cardiac hypertrophy, fibrosis, and remodeling, independent of plasma cholesterol levels. ${ }^{49}$

Galectin-3 is secreted by activated macrophages and a member of a family of proteins including soluble $\beta$-galactosidebinding lectins that have regulatory roles in fibrogenesis, inflammation, tissue repair, and cell proliferation. In HF, galectin-3 promotes myocardial fibrosis and inflammation, which are involved in myocardial remodeling. ${ }^{63}$ Recent studies have reported an association between elevated circulating galectin-3 and poor clinical outcomes in patients with HF. ${ }^{64-66}$ A sub-study of the CORONA trial has reported older patients with systolic HF of ischemic origin, receiving modern pharmacotherapy, who have low levels of galectin-3 may benefit from rosuvastatin treatment. ${ }^{67}$

\section{Neurohormonal activation}

HF severity and mortality is linked to sympathetic nervous system activation, which is characterized by the upregulation of the renin-angiotensin-aldosterone system (RAAS), elevated plasma norepinephrine levels, ${ }^{68,69}$ and enhanced natriuretic peptide concentration from the myocardium. ${ }^{70}$ Statins, by downregulating AT1 receptor activation, ${ }^{46}$ reduce sympathetic nerve activity ${ }^{45}$ and modulate the vascular functions of ET-1 receptors ${ }^{71}$ to attenuate ED and myocardial remodeling in $\mathrm{HF}$.

Further, statins inhibit the RAAS in the vasculature ${ }^{57}$ and myocardium ${ }^{58}$ to ameliorate angiotensin II mediated cardiac hypertrophy. ${ }^{59,72}$ Simvastatin decreases plasma norepinephrine levels and renal sympathetic nerve activity, and normalizes baroreceptor responses in rat HF models. ${ }^{73}$

The natriuretic peptide axis is another important neurohormonal pathway that plays a fundamental role in HF. Plasma concentrations of natriuretic peptides aid in diagnosis and predict HF severity and prognosis. ${ }^{74,75}$ Plasma brain natriuretic peptide (BNP) levels are elevated in ventricular dysfunction. ${ }^{76,77}$ Elevated BNP levels are also associated with reduced functional capacity and impaired oxygen uptake at peak exercise in $\mathrm{HF}^{78}$ Recently, statins have been shown to modulate plasma BNP and its precursor amino-terminal proBNP (NT-proBNP) levels, ${ }^{79}$ thus providing evidence for the neurohormonal downregulating effects of statins in HF.

\section{Ischemia}

Recurrent ischemia is associated with the progression of ischemic cardiomyopathy. ${ }^{73}$ Ischemia may lead to elevated extracellular matrix collagen reduction, cardiomyocyte necrosis, and apoptosis resulting in HF. ${ }^{80}$ Inhibition of cholesterol synthesis reduces macrophage activation, foam cell formation, and plaque thrombogenicity, thus altering the lipid to cell ratio of the atherosclerotic lesion, making the plaque less liable to rupture. Statins promote atherosclerotic plaque stabilization by inhibiting inflammatory macrophages, depleting the lipid core, and strengthening the fibrous cap. Pravastatin inhibits macrophage cholesterol metabolism in in vivo and in vitro studies. ${ }^{81}$ Indeed, statins have been shown to reduce atherothrombotic coronary events in patients with low LDL cholesterol levels, ${ }^{82}$ thus extending anti-ischemic effects beyond plaque stabilization. Laboratory evidence demonstrates that statins reduce the extent of myocardial necrosis, preserve myocardial viability, and improve ventricular function in models of myocardial ischemia. ${ }^{83}$ Statins improve coronary endothelial function and promote angiogenesis, thus reducing ischemia in $\mathrm{HF}^{35,84}$ Statins have also been shown to decrease the incidence of HF in patients with hyperlipidemia through the inhibition of cholesterol biosynthesis and other mechanisms which prevent recurrent ischemia. ${ }^{85}$

\section{Arrhythmia}

Cardiac arrhythmias are common in HF and associated structural heart diseases. Atrial fibrillation (AF) coexists in a third of chronic HF patients and may represent either a cause or a consequence of $\mathrm{HF}^{86} \mathrm{AF}$ is more common with the increasing severity of HF. Ventricular arrhythmia, which is often commonly seen in HF, is a major cause of 
sudden cardiac death. Clinical evidence suggests beneficial effects of statins in atrial and ventricular arrhythmia in HF. ${ }^{87,88}$ Data from a multicenter registry of patients with left ventricular systolic dysfunction have shown statin therapy to be associated with a significant reduction in the incidence of $A F^{87}$ The cumulative rate of ventricular arrhythmia or sudden cardiac death was significantly reduced with statin therapy in ischemic cardiomyopathy patients enrolled in the Multicenter Automatic Defibrillator Implantation Trial-II (MADIT). ${ }^{89}$

Statins reduce the incidence of arrhythmia through plaque stabilization, but a significant reduction in sudden death was reported in nonischemic cardiomyopathy, ${ }^{90}$ suggesting non-cholesterol-lowering effects in decreasing arrhythmic events. Aside from anti-ischemic properties, other proposed mechanisms for the observed lowered incidence of arrhythmias with statin therapy in $\mathrm{HF}^{18}$ are membrane-stabilizing and anti-inflammatory properties as well as improved autonomic function. Further, statins appear to improve left ventricular function and prevent remodeling, thereby decreasing the incidence of ventricular arrhythmias. ${ }^{91}$ In addition, recent experimental data suggest Rac-1 guanosine triphosphatase (GTPase) may contribute to the pathogenesis of $\mathrm{AF}^{92}$ and its suppression by statins may reduce arrhythmias. Nonetheless, recent meta-analyses have provided conflicting reports about the effects of statin therapy in patients with $\mathrm{AF}^{88,93}$ One such study showed that statin therapy is significantly associated with a decreased risk of incidence or recurrence of AF in patients with various cardiovascular conditions (sinus rhythm with a history of previous AF in those undergoing cardiac surgery or after acute coronary syndrome). ${ }^{88}$ This meta-analysis provided robust evidence of the benefit of statins beyond their lipid lowering activity. ${ }^{88}$ In a subsequent meta-analysis of published and unpublished studies of statins in various cardiovascular conditions, short term treatment with statins provided compelling evidence of AF prevention, however, long term treatment showed no protective effect of statins on $\mathrm{AF}^{93}$ Thus, prospective randomized clinical trials may still be needed to establish whether statins are beneficial and are an appropriate therapeutic option in all subgroups of patients for the treatment of AF, particularly HF.

In conclusion, statins exert pleiotropic effects in tandem with their lipid lowering activity to interfere with the pathophysiology of HF. Statins restore normal neurohormonal balance, prevent ventricular remodeling, prevent recurrent ischemia, reduce inflammation, and improve cardiac function in patients with HF. Statin treatment has been shown to favorably affect endothelial function, increase capillary density as well as circulating endothelial progenitor cells, and slow the progression of coronary atherosclerosis. These potential beneficial effects result from both cholesteroldependent and cholesterol-independent actions of statins on the mevalonate pathway. Thus, statins may reverse or attenuate progression and reduce mortality in patients with ischemic and nonischemic HF.

\section{Potential harmful effects of statins in $\mathbf{H F}$}

Statins are often not prescribed for patients with established HF. This is likely to be due to concerns about detrimental effects observed, largely, in retrospective studies. Three hypotheses have been suggested to explain the potential harmful effects of statins in HF.

First, the endotoxin-lipoprotein hypothesis, which postulates that higher levels of cholesterol might be beneficial in HF due to the ability of cholesterol to regulate inflammation. ${ }^{94}$ $\mathrm{HF}$ is associated with increased inflammatory cytokines, which might be partly linked to elevated endotoxin levels. Endotoxins stimulate the release of cytokines in patients with HF. Circulating cholesterol and triglyceride-rich lipoproteins are natural nonspecific buffers of endotoxins, which are capable of binding and detoxifying bacterial lipopolysaccharides. ${ }^{95}$ Thus, lowered circulating cholesterol may result in endotoxemia which is associated with poorer prognosis in HF.

Second, the ubiquinone hypothesis states that inhibition of ubiquinone synthesis in the mevalonate pathway possibly impairs mitochondrial energy production. Ubiquinone is present in all cells and is critical to mitochondrial respiration. Statins inhibit ubiquinone synthesis, which in turn impairs cellular energy production to adversely affect ventricular function and exercise tolerance in HF. Statins also inhibit ubiquinone synthesis, resulting in statin-induced myalgias and myopathy. ${ }^{96}$

Third, the selenoprotein hypothesis postulates that statins interfere with the enzymatic isoprenylation of selenocysteine transfer RNA (tRNA) to inhibit its maturation to functional tRNA molecules, thereby decreasing selenoprotein levels. Statin-induced myopathies have been associated with severe selenoprotein deficiency. ${ }^{97}$

The above three hypotheses, mechanisms, and possible harmful effects of statins in HF are summarized in Table 1. Despite these concerns, statin trials as well as systematic reviews and meta-analyses of statin treatment in heart failure have not established any detrimental effects, but suggest favorable effects in HF populations. ${ }^{18,19}$ 
Table I Hypothesis, mechanism, and effects of statins in heart failure

\begin{tabular}{|c|c|c|}
\hline Hypothesis & Mechanisms & Effects \\
\hline $\begin{array}{l}\text { Endotoxin-lipoprotein } \\
\text { hypothesis }\end{array}$ & $\begin{array}{l}\text { Inhibition of HMG-CoA reductase } \\
\text { resulting in reduced circulating } \\
\text { plasma cholesterol and triglyceride- } \\
\text { rich lipoproteins }\end{array}$ & $\begin{array}{l}\text { - Lowered cholesterol reduces provision of metabolic reserves } \\
\text { and protection in increased resting energy consumption in } \mathrm{HF}^{98} \\
\text { - Low cholesterol is associated with poorer HF outcomes } \\
\text { - Cholesterol and triglyceride-rich lipoproteins bind and detoxify } \\
\text { endotoxin entering into the blood via GIT }{ }^{95} \\
\text { - Endotoxin mediates HF progression via activation and release } \\
\text { of proinflammatory cytokines } \\
\text { - Statin enhances circulating endotoxin levels and further elevates } \\
\text { proinflammatory cytokines to worsen } \mathrm{HF}^{17}\end{array}$ \\
\hline Ubiquinone hypothesis & $\begin{array}{l}\text { Inhibition of ubiquinone synthesis } \\
\text { downstream of the mevalonate } \\
\text { pathway }\end{array}$ & $\begin{array}{l}\text { - Ubiquinone is key to mitochondrial respiration in cells } \\
\text { - Statin decreases ATP production in the myocardium } \\
\text { - Statins inhibit the antioxidant function of ubiquinone and } \\
\text { reduce cellular protection from free radical injury } \\
\text { - Statins adversely affect ventricular function and exercise } \\
\text { tolerance in HF96 } \\
\text { - Statins inhibit ubiquinone synthesis to cause statin-induced } \\
\text { myalgias and myopathy }{ }^{96}\end{array}$ \\
\hline Selenoprotein hypothesis & $\begin{array}{l}\text { Inhibition of selenoprotein synthesis } \\
\text { by blockade of HMG-CoA reductase } \\
\text { in the mevalonate pathway }\end{array}$ & $\begin{array}{l}\text { - Selenoproteins are critical in skeletal and cardiac muscle } \\
\text { metabolism } \\
\text { - Statins decrease selenoprotein production to cause skeletal } \\
\text { and cardiac muscle myopathy }{ }^{99}\end{array}$ \\
\hline
\end{tabular}

Abbreviations: ATP, adenosine triphosphate; GIT, gastrointestinal tract; HF, heart failure; HMG-CoA, hydroxyl methyl glutaryl-coenzyme A.

\section{Clinical experience with statins in HF}

Owing to potential unfavorable effects, earlier statin trials have excluded patients with symptomatic HF. But their pleiotropic actions suggest HF patients may benefit from statin treatment aside from cholesterol lowering effects. These claims have been partially confirmed, as post hoc analyses of statin trials in various cardiovascular conditions showed improved survival in patients with $\mathrm{HF}$ as summarized in Table 2. , $6,10-13,60,82,100-103$ Likewise, retrospective and subgroup analyses of the effects of statins in HF trials which evaluated outcomes of other therapeutic agents showed reduced hospitalization and mortality. ${ }^{104-106}$

\section{Evidence from non-randomized studies}

Many non-randomized studies have provided evidence to support the use of statins in HF. These non-randomized studies evaluated the effects of statins on outcomes in patients with HF and various cardiovascular conditions.

Table 2 Retrospective analyses of statin trials in various cardiovascular conditions

\begin{tabular}{|c|c|c|c|c|c|c|c|}
\hline Study & Sample & Population & HF in population & Intervention & $\begin{array}{l}\text { Duration } \\
\text { (years) }\end{array}$ & $\begin{array}{l}\text { Outcomes in HF } \\
\text { subgroup }\end{array}$ & Findings \\
\hline $4 S^{4}$ & 4444 & $\mathrm{CAD} / \uparrow \mathrm{CHL}$ & 412 & Simvastatin & 5.4 & Mortality & $\downarrow$ \\
\hline CARE $^{10}$ & 4159 & $\mathrm{MI} / \uparrow \mathrm{CHL}$ & 706 & Pravastatin & 5.0 & $\begin{array}{l}\text { Death from } C A D \text {, } \\
E F>40 \% \text { versus } E F<40 \%\end{array}$ & $\downarrow$ \\
\hline LIPID $^{6}$ & 9014 & $\mathrm{MI} /$ unstable angina & None at baseline & Pravastatin & 6.1 & Death & $\downarrow$ \\
\hline MIRACL"' & 3086 & Unstable angina & 253 & Atorvastatin & 0.3 & HF onset/rehospitalization & $\leftrightarrow$ \\
\hline PROSPER $^{60}$ & 5814 & PVD & $\begin{array}{l}\text { NYHA class III-IV } \\
\text { HF excluded }\end{array}$ & Pravastatin & 3.2 & HF hospitalization & $\leftrightarrow$ \\
\hline GREACE $^{100}$ & 1600 & CAD & 118 & Atorvastatin & 3.0 & Death, MI, unstable angina & $\downarrow$ \\
\hline$A-Z^{12}$ & 4497 & ACS & 221 & Simvastatin & 2.0 & New HF onset & $\downarrow$ \\
\hline GRACE $^{103}$ & 19537 & ACS & $N / A$ & Atorvastatin & 3.5 & HF during hospitalization & $\downarrow$ \\
\hline ALLIANCE ${ }^{13}$ & 2442 & CAD & 162 & Atorvastatin & 4.3 & Hospitalization & $\leftrightarrow$ \\
\hline IDEAL 101 & 8888 & Acute MI & 537 & Atorvastatin & 4.8 & Risk of hospitalization & $\leftrightarrow$ \\
\hline $\mathrm{HPS}^{82}$ & 20536 & $\mathrm{DM}, \mathrm{VD}$ & HF excluded & Simvastatin & 5.0 & Hospitalization or death & $\downarrow$ \\
\hline TNT $^{102}$ & 10001 & Stable CAD & 781 & Atorvastatin & 4.9 & Hospitalization & $\downarrow$ \\
\hline
\end{tabular}

Notes: $\leftrightarrow$, no effect; $\downarrow$, decrease; $\uparrow$, increase.

Abbreviations: ACS, acute coronary syndrome; CAD, coronary artery disease; CHL, cholesterol; DM, diabetes mellitus; EF, ejection fraction; MI, myocardial infarction; PVD, peripheral vascular disease; VD, vascular disease; HF, heart failure. 
Generally, statin therapy has been associated with reduced mortality in HF, however, equivocal results have been reported. ${ }^{103}$

A prospective study conducted at the Duke Heart Failure Clinic enrolled 96 consecutive outpatients with ejection fraction $(\mathrm{EF})<40 \%$ and NYHA class II to IV symptoms, and 14 healthy volunteers as a control. ${ }^{107}$ Enrolled patients were on standard care appropriate to disease severity, were clinically observed directly and/or through family interactions during clinic visits, and had telephone follow-up over a 12-month period. They were observed for the occurrence of adverse events such as death, hospitalization for all causes, worsening heart failure, and angina. Combined therapy of ACE inhibitors and $\beta$-blockers was associated with lower CRP levels, improved survival, and reduced outcomes of hospitalization, worsening heart failure, and incidence of angina. Statin therapy had no effect on CRP levels and failed to improve outcome benefits, but did not worsen HF outcomes. ${ }^{107}$ In another prospective cohort study, 6427 cardiologist-diagnosed HF patients (mean age of $69 \pm 11$ years) were followed for 12 months. ${ }^{14}$ Enrolled patients had varying degrees of renal insufficiency. In 2545 of the patients observed, statin use was associated with significantly better survival, after adjustment for other medications, even in advanced renal insufficiency compared with non-statin users. ${ }^{14}$ In the Kaiser Permanente congestive HF cohort of 24,598 patients, Go et al evaluated the association between initiating statin therapy and risk of death and hospitalization among adults who had HF after a median follow-up of 2.4 years. ${ }^{108}$ Statin therapy was associated with a $24 \%$ (hazard ratio [HR] $0.74,95 \%$ confidence interval [CI] 0.72 to 0.80 ) lower risk for death and a $21 \%$ (HR $0.79,95 \% \mathrm{CI}$ 0.74 to 0.85 ) lower risk of hospitalization for HF. Statins were, however, more likely to be prescribed in younger patients and those known to have $\mathrm{CAD}$, diabetes, or hypertension.
The difference in mortality was independent of cholesterol level or coronary disease. ${ }^{108}$

Foody et al evaluated the association between statin use and survival in a large retrospective observational study of 54,940 Medicare beneficiaries hospitalized for HF. ${ }^{109}$ About $16.7 \%$ of the patients primarily diagnosed with HF without contraindications were discharged on statin therapy. Treatment with statin at the time of discharge was associated with significant reduction in mortality at 1 (HR $0.80,95 \% \mathrm{CI}$ 0.76 to 0.84 ) and 3 years (HR $0.82,95 \%$ CI 0.79 to 0.85 ). It is worth noting that the significant reduction in mortality was independent of patient demographics, treatments, physician specialty, and hospital characteristics. There was a significant difference in mortality between statin users and nonusers independent of CAD status or total cholesterol levels. ${ }^{109}$

In conclusion, previous studies have reported decreased hospital admissions, improved surrogate endpoint outcomes, and overall mortality with statin therapy as summarized in Table 3, thus appearing to support its beneficial role in HF. ${ }^{14,109-112}$ The equivocal results reported by the Duke Heart Failure Clinic study may be due to the small sample size of the study, which might have introduced type $2(\beta)$ errors, particularly when it assessed major clinical outcomes. ${ }^{107}$ Further, overlap of treatment groups, particularly of patients that received $\beta$-blockers and statins created difficulty in detecting the effect of each medication on clinical outcomes. In addition, the assessment of CRP and medication use was determined at a single time point, which might have introduced potential intrapatient variability and made longitudinal analysis of the effect of medications on CRP levels impracticable. Statin therapy has been associated with reduced hospital admissions and mortality in non-randomized studies as shown in Table 3. This body of evidence comes from non-randomized studies which are susceptible to confounding and bias and should be interpreted with caution and regarded as "hypothesis-generating."

Table 3 Major non-randomized studies evaluating effect of statins in heart failure outcomes

\begin{tabular}{|c|c|c|c|c|c|}
\hline Study & Sample & Statin & $\begin{array}{l}\text { Follow-up } \\
\text { (months) }\end{array}$ & Outcome & Findings \\
\hline Hognestad et al ${ }^{110}$ & 5301 & Any & 25 & Mortality & Improved mortality \\
\hline Joynt et al ${ }^{107}$ & 96 & Any & 12 & C-reactive protein & No effect \\
\hline Ezekowitz et al ${ }^{14}$ & 6427 & Any & 12 & Mortality & Improved mortality \\
\hline Ray et al ${ }^{\prime \prime \prime}$ & 28828 & Any & 96 & Mortality & Improved mortality \\
\hline Sola et $\mathrm{al}^{112}$ & 446 & Any & 24 & Mortality/hospitalization & Improved outcomes \\
\hline Go et $a^{108}$ & 24598 & Any & 29 & Mortality/hospitalization & Improved outcomes \\
\hline Foody et al ${ }^{109}$ & 54960 & Any & 36 & Mortality & Improved mortality \\
\hline Senthil et $\mathrm{al}^{113}$ & 10510 & Any & 31 & Mortality & Improved mortality \\
\hline Maison et $\mathrm{al}^{1 / 4}$ & 281 & Any & 96 & Mortality & Improved mortality \\
\hline Paloma et al ${ }^{115}$ & 960 & Any & 109 & Mortality & Improved mortality \\
\hline
\end{tabular}




\section{Randomized controlled trials (RCTs) of statins in HF}

Secondary analyses of statin trials in various cardiovascular conditions show improved HF outcomes, though mechanisms are indistinct. RCTs have evaluated the effects of statin treatment on surrogate endpoints as well as major clinical outcomes (hospital admissions and mortality) in HF (Table 4).

Many small scale RCTs show improved cardiac and endothelial function, reduced inflammation and oxidation markers, ${ }^{116-121}$ whereas in other trials, statins had shown neither favorable nor detrimental effects in HF. ${ }^{61,122,123}$ Most of the studies appeared to be insufficiently powered to determine major outcomes such as hospital admissions and mortality, but significantly improved surrogate endpoints in HF. Sola et al ${ }^{119}$ conducted one such study that randomized 108 nonischemic HF patients to atorvastatin $20 \mathrm{mg}$ /day or a matching placebo and followed them up for 12 months. The study observed changes in left ventricular EF (LVEF) determined by transthoracic echocardiography as the primary endpoint and inflammatory and oxidation markers as the secondary endpoint. It observed a significant reduction in inflammatory and oxidation markers and improved LVEF. Interestingly, atorvastatin failed to reduce the frequency of hospital admissions or mortality in HF.
Laufs et al ${ }^{124}$ corroborated the beneficial effect of cerivastatin with improved brachial artery flow mediated dilation, quality of life score, functional ability, and reduced levels of plasminogen activator inhibitor-1 (PAI-1), CRP, and TNF- $\alpha$ in patients with dilated cardiomyopathy in a 4-month follow-up period.

In another study, $60 \mathrm{HF}$ patients of ischemic and nonischemic origin with NYHA class II to III and LVEF $<40 \%$ were randomized to atorvastatin $10 \mathrm{mg}$ or a matching placebo for 4 weeks. ${ }^{125}$ The efficacy was determined by measuring various biomarkers and flow-mediated vasodilatation at the baseline and at 4 weeks. Reactive hyperemia caused by flow mediated vasodilatation increased significantly and there was a consequent reduction in inflammatory markers such as vascular adhesion molecule-1 (VCAM-1), IL-6, and TNF- $\alpha .{ }^{125}$ These evidences suggest statins could be beneficial in both ischemic and nonischemic HF.

Conversely, neither favorable nor detrimental effects on cardiac function, endothelial function, and inflammatory markers were observed with studies that used high doses of statins in $\mathrm{HF}^{61,123}$ In one such study, 15 patients with Non-Ischemic Cardiomyopathy (NICM) on optimal heart failure treatment were enrolled in a randomized, doubleblind, placebo-controlled, cross over trial. ${ }^{123}$ Patients were

Table 4 Randomized controlled trials of statins in heart failure

\begin{tabular}{|c|c|c|c|c|c|}
\hline Study & Sample & Intervention & $\begin{array}{l}\text { Duration } \\
\text { (months) }\end{array}$ & Outcome & Findings \\
\hline GISSI-HF'5 & 4574 & Rosuvastatin $10 \mathrm{mg}$ & 46 & Mortality/CV admission & $\leftrightarrow$ \\
\hline CORONA $^{16}$ & 5011 & Rosuvastatin $10 \mathrm{mg}$ & 32 & Mortality/CV admission & $\leftrightarrow$ mortality, $\downarrow$ CV admission \\
\hline Vrtovec et al ${ }^{116}$ & 110 & Atorvastatin $10 \mathrm{mg}$ & 12 & Sudden cardiac death & $\downarrow$ \\
\hline Wojnicz et al ${ }^{117}$ & 74 & Atorvastatin $40 \mathrm{mg}$ & 6 & LVEF and NYHA class & $\uparrow$ LVEF; $\downarrow$ NYHA class \\
\hline Xie et al ${ }^{118}$ & 119 & Atorvastatin 10/20 mg & 12 & LVEF, QTc, and QTcd & $\uparrow \mathrm{LVEF} ; \downarrow$ QTc and $\downarrow$ QTcd \\
\hline Yamada et al ${ }^{120}$ & 38 & Atorvastatin $10 \mathrm{mg}$ & 31 & LVEF and BNP & $\uparrow$ LVEF; $\downarrow$ BNP \\
\hline Krum et $\mathrm{al}^{61}$ & 95 & Rosuvastatin $10-40 \mathrm{mg}$ & 6 & LVEF & $\leftrightarrow$ LVEF \\
\hline Sola et al ${ }^{119}$ & 108 & Atorvastatin $20 \mathrm{mg}$ & 12 & LVEF, markers & $\uparrow \mathrm{LVEF} ; \downarrow$ markers \\
\hline Hamaad et al ${ }^{122}$ & 23 & Atorvastatin 40 mg & 3 & HRV & $\leftrightarrow \mathrm{HRV}$ \\
\hline Node et al ${ }^{121}$ & 51 & Simvastatin $5-10 \mathrm{mg}$ & 3 & LVEF, NYHA, markers, and BNP & $\begin{array}{l}\uparrow \mathrm{LVEF} ; \downarrow \text { BNP, and } \downarrow \\
\text { markers }\end{array}$ \\
\hline Erbs et $\mathrm{al}^{126}$ & 42 & Rosuvastatin $40 \mathrm{mg}$ & 3 & $\begin{array}{l}\text { LVEF, FMD, CPCs, VEGF, and } \\
\text { oxLDL }\end{array}$ & $\begin{array}{l}\uparrow \mathrm{LVEF}, \uparrow \mathrm{CPCs}, \uparrow \mathrm{FMD}, \\
\uparrow \mathrm{VEGF} \text { and } \downarrow \text { oxLDL }\end{array}$ \\
\hline Bleske et $\mathrm{al}^{123}$ & 15 & Atorvastatin $80 \mathrm{mg}$ & 3 & LVEF, markers, BNP, and HRV & $\leftrightarrow$ \\
\hline Tsutamoto et al ${ }^{127}$ & 63 & Atorvastatin 5/R2.5 mg & 6 & LVEF, markers, and BNP & $\uparrow \mathrm{A}, \mathrm{R} \leftrightarrow$ \\
\hline Andreou et $\mathrm{al}^{128}$ & 60 & Rosuvastatin $10 \mathrm{mg}$ & 1 & MPO & MPO $\downarrow$ \\
\hline Tousoulis et $\mathrm{al}^{125}$ & 60 & Rosuvastatin $10 \mathrm{mg}$ & I & CPCs, FMD, and oxLDL & $\uparrow \mathrm{CPCs}, \uparrow \mathrm{FMD}, \downarrow$ oxLDL $\downarrow$ \\
\hline Bielecka et al $^{129}$ & 68 & Atorvastin 10-40 mg & 6 & 6MWT, NYHA, and markers & $\uparrow$ 6MWT, $\downarrow$ markers, $\downarrow$ NYHA \\
\hline Tousoulis et $\mathrm{al}^{130}$ & 38 & Atorvastatin $20 \mathrm{mg}$ & 1 & Blood flow, markers & $\uparrow$ Blood flow, $\downarrow$ markers \\
\hline Horwich et $\mathrm{al}^{|3|}$ & 26 & Atorvastatin $10 \mathrm{mg}$ & 3 & MSNA, LVEF, BNP, and QoL & $\leftrightarrow$ \\
\hline
\end{tabular}

Notes: $\leftrightarrow$, No effect; $\uparrow$, Increase; $\downarrow$, Decrease.

Abbreviations: 6MWT, six minute walk test; A, atorvastatin; BNP, brain natriuretic peptide; CPCs, circulating progenitor cells; CV, cardiovascular; FMD, flow-mediated dilation; HRV, heart rate variability; LVEF, left ventricular ejection fraction; markers, inflammatory biomarkers; MPO, myeloperoxidase; MSNA, muscle sympathetic nerve activity; NYHA, New York Heart Association; oxLDL, oxidized low-density lipoprotein; QoL, quality of life; QTc, corrected QT interval; QTcd, corrected QT interval dispersion; R, rosuvastatin; S, simvastatin; VEGF, vascular endothelial growth factor. 
randomized to atorvastatin $80 \mathrm{mg}$ /day or matching placebo for the 12-week treatment period with a minimum of an 8 -week washout period. The study evaluated surrogate markers such as NT-proBNP, high-sensitivity CRP, oxidized LDL antibody, soluble receptor TNF- $\alpha$, TNF- $\alpha$, circulating levels of intercellular adhesion molecule-1 (ICAM-1), VCAM-1, and P-selectin; all are parameters of noninvasive endothelial function and heart rate variability. ${ }^{123}$ Statin therapy reduced LDL but was inert to the surrogate endpoints. Statin was neither beneficial nor detrimental as determined by surrogate marker measures. Similarly, the UNIVERSE study randomized 95 ischemic and nonischemic HF patients to rosuvastatin $40 \mathrm{mg}$ /day or a matching placebo in addition to standard optimal therapy for a period of 6 months in a double-blind fashion. ${ }^{61}$ The highest dose of rosuvastatin markedly reduced LDL cholesterol, but failed to improve cardiac function among patients in the treatment group.

Generally, many small randomized studies show statins to improve surrogate markers and endpoints, but do not reduce the frequency of hospitalization and mortality in $\mathrm{HF}$ (Table 4). ${ }^{116-121,125,127,128,131}$ It appears the effect of statins shown in patients with $\mathrm{HF}$ varies among the different types of statins employed.

\section{Evidence from systematic reviews and meta-analyses}

Evidence for statin therapy in HF mainly comes from nonrandomized studies which evaluated its effects on clinical outcomes in patients with HF and various cardiovascular conditions. ${ }^{4,6,10-14,60,82,100-103,107,108,110-112}$ Subgroup and post hoc analyses of statin trials in various cardiovascular conditions and HF trials that evaluated other pharmacological agents too provided substantial evidence for statin use in HF. ${ }^{104-106}$

Several systematic reviews and meta-analyses have been conducted to synthesize evidence for statin therapy in reducing major adverse events in HF. van der Harst et $\mathrm{al}^{19}$ conducted the first systematic review mainly from retrospective, nonrandomized trials and a few prospective randomized studies of statin treatment in HF. The researchers found that there is a paucity of prospective data required to determine the effect of statins on clinical outcomes in HF and concluded that available experimental, post hoc data, observational data, and theoretical considerations are inconsistent. The authors reported that: (1) lower cholesterol levels are associated with poorer outcomes in HF patients and may be related to the function of cholesterol as a scavenger for harmful endotoxins; (2) statins in HF may adversely affect mitochondrial function through inhibition of ubiquinone; and (3) statins may decrease selenoproteins, which could result in decreased myocardial function. The researchers concluded that statin treatment may favor HF and recommended a large randomized clinical trial.

Ramasubbu et al's ${ }^{18}$ meta-analysis from 13 studies - eleven retrospective studies and two prospective studies - reported that statin treatment favored HF with a significant $26 \%$ decrease in relative risk of mortality. Conversely, two recent meta-analyses performed on randomized clinical trials did not show improved survival with statin in HF. ${ }^{132,133}$ It appears that the majority of patient data came from CORONA ${ }^{15}$ and GISSI-HF ${ }^{16}$ trials which randomized older patients to low dose rosuvastatin or matching placebo that may have skewed the summary statistic towards the results of these two large trials. From the various studies, low and moderate doses of statins seem to have better outcomes than high doses of statins in patients with HF. However, these claims were not confirmed when investigated with meta regression models and subgroup analysis. Similarly, the age and sex of patients did not influence the outcomes of HF with statin therapy in any of the meta-analyses.

\section{Recent evidence for statin therapy in HF}

To provide more conclusive data on whether or not statins confer survival and other outcome benefits in HF, CORONA $(2007)^{15}$ and GISSI-HF $(2008)^{16}$ trials were conducted and sufficiently powered to evaluate outcomes of $\mathrm{HF}$ with statin treatment.

The CORONA study was a large randomized, placebo controlled trial of rosuvastatin $10 \mathrm{mg}$ versus a placebo in patients with chronic symptomatic systolic HF of ischemic etiology. ${ }^{15}$ The study enrolled 5011 patients aged $\geq 60$ years with NYHA class II symptoms and an EF of $<35 \%$, or NYHA class III to IV symptoms and an EF of $<40 \%$ with an average of 3 years follow-up. Rosuvastatin did not confer survival benefits, but reduced the number of HF hospitalizations in older patients with systolic HF. The CORONA trial may have failed to improve the primary outcome due to enrollment of elderly patients who may have had many comorbidities which could have attenuated the benefits. Further, the drug may have potentially interacted with the complex medical therapy of the geriatric population.

Moreover, as the CORONA study recruited ischemic HF patients, a significant number of patients could have developed a statin tolerance due to the long period of exposure from treatment of CAD, and prevention and treatment of $\mathrm{HF}$, which meant they may have required a higher dose or a different statin to elicit the desired response to bring about a significant survival benefit. However, it is 
reassuring to note that post hoc analyses of the CORONA trial show HF patients of ischemic origin with low levels of galectin- $3^{67}$ and NT-proBNP ${ }^{55}$ may benefit from rosuvastatin treatment. The findings do not recommend the general use of statins in HF, but endorse their use in ischemic heart disease patients with plasma galectin- 3 concentrations lower than $19.0 \mathrm{ng} / \mathrm{mL}$ and NT-proBNP less than $103 \mathrm{pmol} / \mathrm{L}$ $(868 \mathrm{pg} / \mathrm{mL})$. This observation complements that of the Heart Protection Study (HPS), where patients with low levels of BNP benefited from simvastatin treatment. ${ }^{134}$ Nonetheless, the presence of HF was not recorded at baseline, and it was impossible to directly estimate the effect of simvastatin in patients with and without HF at randomization in the HPS. This evidence is from a retrospective analysis, which may thus be considered as hypothesis-generating and should be confirmed in a prospective study.

The GISSI-HF trial was a multicenter, randomized, doubleblind study that assessed the effect of n-3 polyunsaturated fatty acids and rosuvastatin $10 \mathrm{mg}$ versus placebo on the cardiovascular morbidity and mortality of patients with chronic symptomatic HF. ${ }^{16}$ This study enrolled $4574 \mathrm{HF}$ patients and employed broad eligibility criteria, requiring NYHA class II to IV symptoms of any etiology. There were no exclusions based on EF or baseline cholesterol levels. The GISSI-HF trial also did not show any significant effect of rosuvastatin on clinical outcomes in patients with chronic $\mathrm{HF}$ of ischemic and nonischemic etiologies after 3 years of follow-up. The GISSI-HF and CORONA studies reported minimal adverse drug events and statin therapy did not worsen HF outcomes, even in older patients with possibly compromised myocardium. Thus, it may be concluded that statins are safe in HF.

A recent study appraised the effect of statin on all-cause mortality in a large cohort of 10,510 consecutive patients (mean age 72 years) from the Veterans Affairs health system, with ischemic and nonischemic HF over 3 years. ${ }^{113}$ The study also assessed the effect of incremental duration of statin therapy on mortality. Statin use was associated with significantly lower all-cause mortality among the veterans. Most of the enrolled patients used simvastatin and atorvastatin, which might have accounted for the marked improvement in survival. ${ }^{113}$ Patients were comparable to those of the GISSI-HF study, ${ }^{16}$ which recounted a nonsignificant $29 \%$ mortality compared with the placebo group, as both studies recruited elderly patients with ischemic and nonischemic HF. In this study, patients who used statins for $<25 \%$ of the 3 -year follow-up had no benefit, but survival was apparent when statin use was $>25 \%$ of the follow-up duration, suggesting compliance as an important confounding factor. A major weakness of the GISSI-HF study was noncompliance, as about a third of the study population were not compliant with statin treatment for various reasons and may have influenced its result. Likewise the Veterans Affairs study was similar to the CORONA study (mean age: 73 years, mortality rate: $11.9 \%$ ), but the reason for the disparity in mortality rate recounted remains unclear. Differences in revascularization rates, aggressive lipid control, and other comorbid conditions ${ }^{135}$ may have accounted for the disparity in mortality rates. The CORONA and GISSI-HF studies assessed the effect of one type of statin at a low dose, thus the insignificant results provide inconclusive evidence for the class effect of statins in HF. The majority of patients in the Veteran Affairs health system study used simvastatin and atorvastatin; therefore, an evaluation of the effects of various statins in patients with both ischemic and nonischemic HF may be required.

Similarly, a prospective study assessed the effects of statin therapy in 960 elderly HF patients of ischemic and nonischemic etiologies for a maximum follow-up of 9 years. ${ }^{115}$ Most patients were prescribed atorvastatin or simvastatin and statin use generally was associated with improved survival (HR $0.45,95 \%$ CI 0.37 to 0.54 ) for HF. ${ }^{115}$ In contrast to the CORONA and GISSI-HF studies, statin was independently and significantly associated with lower mortality after adjusting for all confounders, such as concurrent medication, concurrent therapies, comorbid conditions, gender, HF etiology, HF duration, cholesterol level, LVEF, NYHA class, and sex.

Rosuvastatin, used in the CORONA and GISSI-HF studies, is hydrophilic and employs active transport into hepatocytes to exert its effect. ${ }^{2,3}$ It penetrates poorly into extra hepatic tissues; thus, it has less risk of adverse effects, but has a very low uptake by cardiac muscles to exert the pleiotropic effects believed to contribute greatly to attenuate HF symptoms.

Conversely, atorvastatin and other lipophilic statins commonly prescribed in clinics appear to have higher levels of exposure in extra hepatic tissues and very high uptake into cardiac muscles. ${ }^{2,3}$ It appears that the effect of statins should not be considered a class effect since small and large scale trials that employed rosuvastatin appeared not to have had a beneficial effect in HF. In addition, a recent meta-analysis of RCTs, which included the CORONA and GISSI-HF trials, suggests lipophilic statins have a significant outcome benefit which was not observed in patients randomized to rosuvastatin or placebo. ${ }^{133}$ However, a class effect of statins at relatively low doses has been reported in elderly cohorts 
of congestive HF with atorvastatin, simvastatin, pravastatin, and lovastatin without rosuvastatin in a large population study. ${ }^{136}$

Maison et $\mathrm{al}^{114}$ recently followed a cohort of 281 chronic HF patients after hospital admission through a search of the health insurance and national mortality data base for 1 year and 8 years, respectively. The use of $\beta$-blockers and statins was associated with statistically significant survival ahead of ACE inhibitors, spironolactone, and diuretics after controlling for confounders using multivariate analysis. Statin therapy was associated with better survival at 8 years. The findings correspond with those of the prospective study that followed patients for about 9 years, suggesting that statins may reduce mortality after longer follow-ups. ${ }^{115}$

Given that this recent evidence for statin therapy comes from non-randomized studies which suffer from threats of internal validity arising from risk of confounding and bias, the robust study design and statistical analyses employed by Thambidorai et $\mathrm{al}^{113}$ and Gastelurrutia et $\mathrm{al}^{115}$ and Maison et al, ${ }^{114}$ eliminate or partly address the bias. Granted that, in these studies, the benefit of statins was assessed in real life healthcare settings without strict inclusion criteria questioning the external validity of RCTs, these findings complement previous evidence provided by small RCTs that employed lipophilic statins. ${ }^{116,117,121}$ The two recent large trials - CORONA ${ }^{15}$ and GISSI-HF ${ }^{16}$ - confirmed the surrogate effects exhibited by statins in small randomized trials but failed to ultimately confer survival benefit. The choice of statins, dose, as well as patient background, may possibly have accounted for the findings of the CORONA and GISSI-HF studies in contrast with earlier and recent studies. On the other hand, evidence from recent studies, though non-randomized, complements the findings of the small randomized trials but seems to suggest lipophilic statins provide better outcomes than hydrophilic statins in patients with HF. ${ }^{113,115}$

\section{Statins and HF comorbid conditions}

Comorbidities are common in patients with HF. While some of these contribute to the underlying pathogenesis, others may lead to the progression, associated poor prognosis, and consequently increase mortality in HF patients. Germane to appropriate management of these comorbidities exists the concern of polypharmacy in hitherto overburdened HF patients.

Hypertension causes or coexists with $\mathrm{HF}$ and its management in HF could be challenging. Statins possess many pleiotropic effects including improvement in endothelial function, reduction in inflammation and oxidative stress, and downregulation of angiotensin II receptors and endothelin, which would suggest that statins may reduce blood pressure in patients with hypertension. Indeed, evidence from various experimental models suggests antihypertensive actions, though clinical evidence has been inconclusive. ${ }^{137}$ Statins may augment actions of ACE inhibitors, ARBs, and $\beta$-blockers, which double as antihypertensive and conventional pharmacological agents for HF. ${ }^{138}$

Further, hyperuricemia is frequently present in chronic HF and has been attributed to increased production or decreased urinary excretion of uric acid (UA) or both in a compromised circulation. ${ }^{135}$ An elevated plasma level of UA is linked with a wide variety of injurious processes comprising increased inflammatory markers, cell apoptosis, and ED, ${ }^{139}$ which could cumulatively worsen HF. Serum UA is known to be a marker of HF prognosis and mortality ${ }^{140-142}$ and statins have been shown to decrease UA levels by increasing urate excretion. ${ }^{143,144}$

Chronic renal failure (CRF) is a condition which often complicates pharmacotherapy in HF. CRF is also associated with hyperuricemia worsened by diuretic therapy, which is critical in the management of fluid retention, but increases UA levels. Statins have been shown to improve renal function partly through their modulation of the mevalonate pathway to reduce oxidative stress, inflammation, and hypercoagulability, ${ }^{145}$ all of which are linked with renal dysfunction via increased atherosclerosis and ED. ${ }^{144,146}$

Chronic obstructive pulmonary disease (COPD) is a common comorbid condition with incidence varying from $20 \%$ to $30 \%$ in patients with $\mathrm{HF} .{ }^{147}$ COPD is an independent predictor of mortality in $\mathrm{HF} .{ }^{148}$ Beta-adrenergic agonists are commonly prescribed as mainstay therapy in COPD, but have been shown in a meta-analysis to significantly increase the risk of cardiovascular events such as tachycardia, AF, myocardial infarction, and HF. ${ }^{149}$ The current therapy relieves symptoms and reduces hospitalization, but does not change disease progression or reduce mortality. ${ }^{150}$ Statins inhibit isoprenoid production on the mevalonate pathway to reduce inflammation (systemic and pulmonary), thereby improving exercise tolerance and reducing mortality in patients with COPD. ${ }^{151,152}$

Statins exert various molecular mechanisms that may modulate the pathophysiology to an extent that may be identical to or even seem to overlap those of currently recommended HF therapies. Additionally, statins may favorably modulate the pathogenesis of HF comorbidities and possibly reverse and/or reduce progression as well as issues associated with polypharmacy in patients with HF. Figure 1 illustrates how statins influence the pathophysiology 


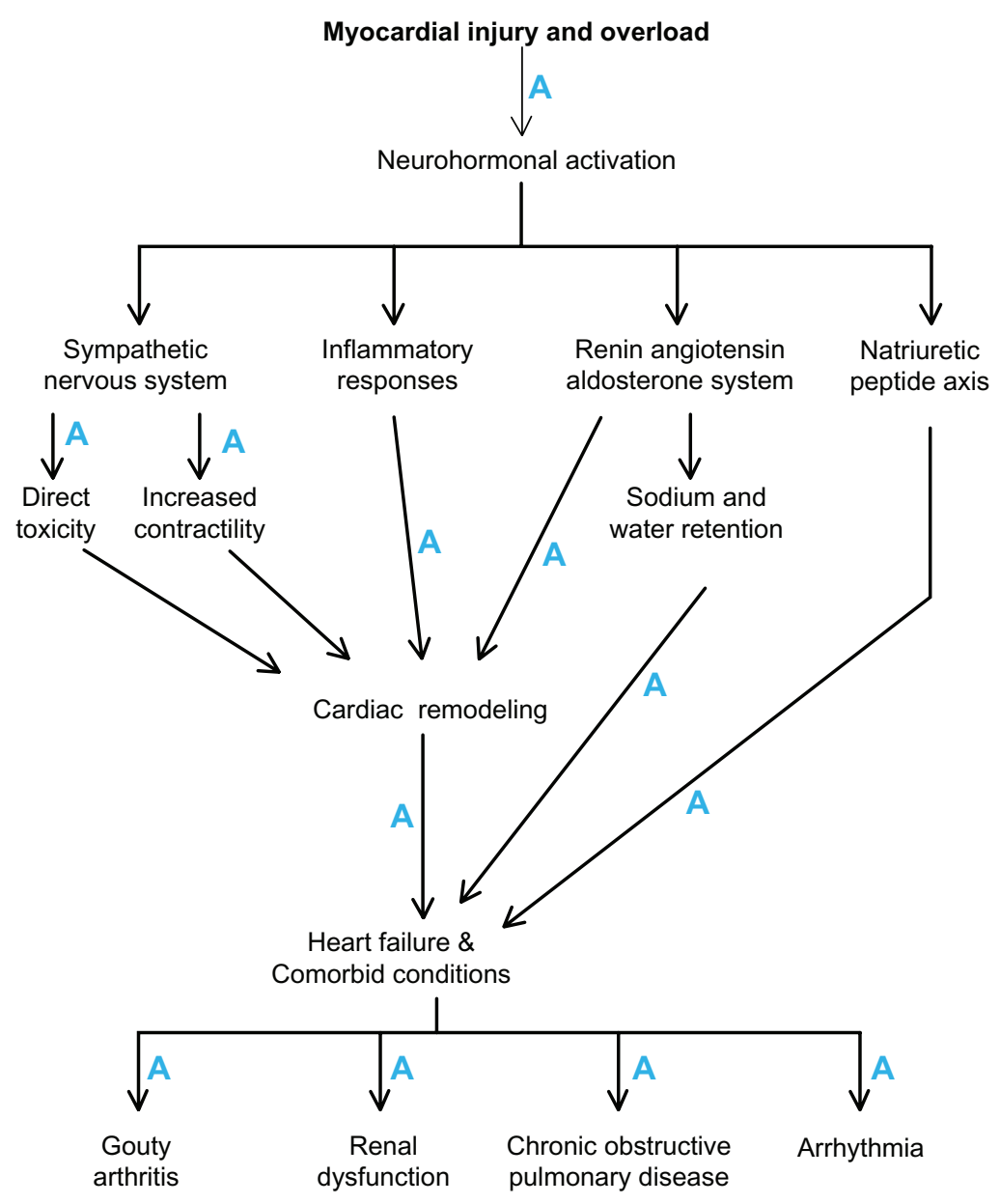

Figure I Statins influence the pathophysiological mechanisms in heart failure (indicated by A).

of HF and its comorbidities. Therefore, statins could merit second line treatment consideration in HF guidelines.

Further research is required to clarify whether statins are still beneficial in HF and warrants consideration into guidelines for the treatment of HF. A sufficiently powered randomized trial to evaluate the effect of other statins apart from rosuvastatin in HF is necessary. In countries where another statin trial in HF is unethical and unlikely, a comparative effectiveness research study is required to compare the efficacies of various statins in patients with HF using data from registries, hospital records, and insurance claims. Alternatively, a direct head to head comparison of the two potent statins (rosuvastatin and atorvastatin) may be ethical since no eligible patients are denied treatment or given a placebo. In addition, an indirect comparison meta-analysis of RCTs which compared statin versus placebo or no statin treatment in HF may be required in the absence of adequately powered head-to-head comparison studies to investigate whether statins are comparable or some types have superior efficacy over others. ${ }^{153}$

\section{Conclusion}

Statin therapy for hypercholesterolemia and primary and secondary prevention of CAD has been established, however, their effects on HF survival remain unclear. The latest evidence from prospective but non-randomized studies complements that of small randomized statin trials in HF and suggests lipophilic statins provide better clinical outcomes than hydrophilic statins. We therefore recommend a randomized trial to evaluate the class effect of statins in HF, but until sufficient evidence is amassed, statin treatment should be based on recommendations from guidelines. Our evidence shows that statins modulate the pathophysiology of HF to an extent that may be identical or even overlap recommended HF therapies. Moreover, statins exert mechanisms on various pathways to reduce or reverse progression of many HF comorbidities beyond the therapeutic actions of some of the mainstay medical therapies and could, in the worse scenario, merit second line or adjuvant therapy consideration in treatment guidelines for HF. 


\section{Acknowledgments}

This research was funded by Monash University Sunway Campus.

\section{Disclosure}

The authors report no conflicts of interest in this work.

\section{References}

1. McMurray JJ, Adamopoulos S, Anker SD, et al; ESC Committee for Practice Guidelines. ESC guidelines for the diagnosis and treatment of acute and chronic heart failure 2012: The Task Force for the Diagnosis and Treatment of Acute and Chronic Heart Failure 2012 of the European Society of Cardiology. Developed in collaboration with the Heart Failure Association (HFA) of the ESC. Eur J Heart Fail. 2012;14(8):803-869.

2. Wierzbicki AS, Poston R, Ferro A. The lipid and non-lipid effects of statins. Pharmacol Ther. 2003;99(1):95-112.

3. Schachter M. Chemical, pharmacokinetic and pharmacodynamic properties of statins: an update. Fundam Clin Pharmacol. 2005; 19(1):117-125.

4. Randomized trial of cholesterol lowering in 4444 patients with coronary heart disease:the Scandinavian Simvastatin Survival Study (4S). Lancet. 1994;344(8934):1383-1389.

5. Shepherd J, Cobbe SM, Ford I, et al. Prevention of coronary heart disease with pravastatin in men with hypercholesterolemia. West of Scotland Coronary Prevention Study Group. N Engl J Med. 1995; 333(20):1301-1307.

6. Prevention of cardiovascular events and death with pravastatin in patients with coronary heart disease and a broad range of initial cholesterol levels. The Long-Term Intervention with Pravastatin in Ischaemic Disease (LIPID) Study Group. N Engl J Med. 1998;339(19):1349-1357.

7. Laufs U, Kilter H, Konkol C, Wassmann S, Böhm M, Nickenig G. Impact of HMG CoA reductase inhibition on small GTPases in the heart. Cardiovasc Res. 2002;53(4):911-920.

8. Laufs U, Liao JK. Post-transcriptional regulation of endothelial nitric oxide synthase mRNA stability by Rho GTPase. J Biol Chem. 1998; 273(37):24266-24271.

9. Laufs U, Liao JK. Isoprenoid metabolism and the pleotropic effects of statins. Curr Atheroscler Rep. 2003;5(5):372-378.

10. Sacks FM, Pfeffer MA, Moye LA, et al. The effect of pravastatin on coronary events after myocardial myocardial infarction in patients with average cholesterol levels.Cholesterol and Recurrent Events trial investigators. $N$ Engl J Med. 1996;335(14):1001-1009.

11. Schwartz GG, Olsson AG, Ezekowitz MD, et al; Myocardial Ischemia Reduction with Aggressive Cholesterol Lowering (MIRACL) Study Investigators. Effects of atorvastatin on early recurrent ischemic events in acute coronary syndromes: the MIRACL study: a randomised controlled trial. JAMA. 2001;285(13):1711-1718.

12. de Lemos JA, Blazing MA, Wiviott SD, et al; Investigators. Early intensive versus a delayed conservative simvastatin strategy in patients with acute coronary syndromes: phase $\mathrm{Z}$ of the $\mathrm{A}$ to $\mathrm{Z}$ trial. JAMA. 2004;292(11):1307-1316.

13. Koren MJ, Hunninghake DB; ALLIANCE Investigators. Clinical outcomes in managed care patients with coronary heart diseas treated agressively in lipid-lowering disease management clinics: the alliance study. J Am Coll Cardiol. 2004;44(9):1772-1779.

14. Ezekowitz J, McAlister FA, Humphries KH, et al; APPROACH Investigators. The association among renal insufficiency, pharmacotherapy, and outcomes in 6,427 patients with heart failure and coronary artery disease. J Am Coll Cardiol. 2004;44(8): 1587-1592.

15. Kjekshus J, Apetrei E, Barrios V, et al; CORONA Group. Rosuvastatin in older patients with systolic heart failure. $N$ Engl $\mathrm{J}$ Med. 2007;357(22):2248-2261.
16. Tavazzi L, Maggioni AP, Marchioli R, et al; Gissi-HF Investigators. Effect of rosuvastatin in patients with chronic heart failure (the GISSI-HF trial): a randomised, double-blind, placebo-controlled trial. Lancet. 2008;372(9645):1231-1239.

17. Rauchhaus M, Coats AJ, Anker SD. The endotoxin-lipoprotein hypothesis. Lancet. 2000;356(9233):930-933.

18. Ramasubbu K, Estep J, White DL, Deswal A, Mann DL. Experimental and clinical basis for the use of statins in patients with ischemic and nonischemic cardiomyopathy. J Am Coll Cardiol. 2008;51(4): 415-426.

19. van der Harst P, Voors AA, van Gilst WH, Böhm M, van Veldhuisen D. Statins in the treatment of chronic heart failure: a systematic review. PLoS Med. 2006;3(8):e333.

20. Furchgott RF, Zawadzki JV. The obligatory role of endothelial cells in the relaxation of arterial smooth muscle by acetylcholine. Nature. 1980;288(5789):373-376.

21. Rubanyi GM, Romero JC, Vanhoutte PM. Flow-induced release of endothelium-derived relaxing factor. Am J Physiol. 1986;250(6 Pt 2): H1145-H1149.

22. Libby P, Aikawa M, Jain MK. Vascular endothelium and atherosclerosis. Handb Exp Pharmacol. 2006;(176 Pt 2):285-306.

23. Davignon J, Ganz P. Role of endothelial dysfunction in atherosclerosis. Circulation. 2004;109(23 Suppl 1):III27-III32.

24. Bauersachs J, Widder JD. Endothelial dysfunction in heart failure. Pharmacol Rep. 2008;60(1):119-126.

25. Ramsey MW, Goodfellow J, Jones CJ, Luddington LA, Lewis MJ, Henderson AH. Endothelial control of arterial distensibility is impaired in chronic heart failure. Circulation. 1995;92(11):3212-3219.

26. Buus NH, Bøttcher M, Hermansen F, Sander M, Nielsen TT, Mulvany MJ. Influence of nitric oxide synthase and adrenergic inhibition on adenosine-induced myocardial hyperemia. Circulation. 2001;104(19):2305-2310.

27. Vásquez-Vivar J, Kalyanaraman B, Martásek P, et al. Superoxide generation by endothelial nitric oxide synthase: the influence of cofactors. Proc Natl Acad Sci U S A. 1998;95(16):9220-9225.

28. Borlaug BA, Melenovsky V, Russell SD, et al. Impaired chronotropic and vasodilator reserves limit exercise capacity in patients with heart failure and a preserved ejection fraction. Circulation. 2006;114(20): $2138-2147$.

29. Laufs U, La Fata V, Plutzky J, Liao JK. Upregulation of endothelial nitric oxide synthase by HMG-CoA reductase inhibitors. Circulation. 1998;97(12):1129-1135.

30. von Haehling S, Anker SD, Bassenge E. Statins and the role of nitric oxide in chronic heart failure. Heart Fail Rev. 2003;8(1):99-106.

31. Vaughan CJ, Murphy MB, Buckley BM. Statins do more than just lower cholesterol. Lancet. 1996;348(9034):1079-1082.

32. Hernández-Perera O, Pérez-Sala D, Navarro-Antolín J, et al. Effects of the 3-hydroxy-3-methylglutaryl-CoA reductase inhibitors, atorvastatin and simvastatin, on the expression of endothelin-1 and endothelial nitric oxide synthase in vascular endothelial cells. J Clin Invest. 1998;101(12): 2711-2719.

33. Katz S, Khan T, Zeballos GA, et al. Decreased activity of the L-argininenitric oxide metabolic pathway in patients with congestive heart failure. Circulation. 1999;99(16):2113-2117.

34. Datta SR BA, Greenberg ME. Cellular survival: a play in three Akts. Genes Dev. 1999;13(22):2905-2927.

35. Kureishi Y, Luo Z, Shiojima I, et al. The HMG-CoA reductase inhibitor simvastatin activates the protein kinase Akt and promotes angiogenesis in normocholesterolemic animals. Nat Med. 2000;6(9): $1004-1010$.

36. Williams JK, Sukhova GK, Herrington DM, Libby P. Pravastatin has cholesterol-lowering independent effects on the artery wall of atherosclerotic monkeys. J Am Coll Cardiol. 1998;31(3):684-691.

37. Jones SP, Greer JJ, van Haperen R, Duncker DJ, de Crom R, Lefer DJ. Endothelial nitric oxide synthase overexpression attenuates congestive heart failure in mice. Proc Natl Acad Sci U S A. 2003; 100(8):4891-4896. 
38. Amudha K, Choy AM, Mustafa MR, Lang CC. Short-term effect of atorvastatin on endothelial function in healthy offspring of parents with type 2 diabetes mellitus. Cardiovasc Ther. 2008;26(4):253-261.

39. Egashira K, Hirooka Y, Kai H, et al. Reduction in serum cholesterol with pravastatin improves endothelium dependent coronary vasomotion in patients with hypercholesterolemia. Circulation. 1994;89(6): $2519-2524$.

40. Stroes ES, Koomans HA, de Bruin TW, Rabelink TJ. Vascular function in the forearm of hypercholesterolaemic patient's off and on lipidlowering medication. Lancet. 1995;346(8973):467-471.

41. Levine B, Kalman J, Mayer L, Fillit HM, Packer M. Elevated circulating levels of tumor necrosis factor in severe chronic heart failure. $N$ Engl J Med. 1990;323(4):236-241.

42. Packer M. Is tumor necrosis factor an important neurohormonal mechanism in chronic heart failure? Circulation. 1995;92(6): 1379-1382.

43. Pinsky DJ, Cai B, Yang X, Rodriguez C, Sciacca RR, Cannon PJ. The lethal effects of cytokine-induced nitric oxide on cardiac myocytes are blocked by nitric oxide synthase antagonism or transforming growth factor beta. J Clin Invest. 1995;95(2):677-685.

44. Pahan K, Sheikh FG, Namboodiri AM, Singh I. Lovastatin and phenylacetate inhibit the induction of nitric oxide synthase and cytokines in rat primary astrocytes, microglia, and macrophages. J Clin Invest. 1997;100(11):2671-2679.

45. Rosenson RS, Tangney CC, Casey LC. Inhibition of proinflammatory cytokine production by pravastatin. Lancet. 1999;353(9157): 983-984.

46. Grip O, Janciauskiene S, Lindgren S. Pravastatin down-regulates inflammatory mediators in human monocytes in vitro. Eur J Pharmacol. 2000;410(1):83-92.

47. Goldstein JL, Brown MS. Regulation of the mevalonate pathway. Nature. 1990;343(6257):425-430.

48. Casey PJ. Protein lipidation in cell signaling. Science. 1995; 268(5208):221-225.

49. Dechend R, Fiebeler A, Park JK, et al. Amelioration of angiotensin II-induced cardiac injury by a 3-hydroxy-3-methylglutaryl coenzyme a reductase inhibitor. Circulation. 2001;104(5):576-581.

50. Ridker PM, Danielson E, Fonseca FA, et al; JUPITER Study Group. Rosuvastatin to prevent vascular events in men and women with elevated C-reactive protein. N Engl J Med. 2008;359(21):2195-2207.

51. Thomas CV, Coker ML, Zellner JL, Handy JR, Crumbley AJ 3rd, Spinale FG. Increased matrix metalloproteinase activity and selective upregulation in LV myocardium from patients with end-stage dilated cardiomyopathy. Circulation. 1998;97(17):1708-1715.

52. Bellosta S, Via D, Canavesi M, et al. HMG-CoA reductase inhibitors reduce MMP-9 secretion by macrophages. Arterioscler Thromb Vasc Biol. 1998;18(11):1671-1678.

53. Aikawa M, Rabkin E, Sugiyama S, et al. An HMG-CoA reductase inhibitor, cerivastatin, suppresses growth of macrophages expressing matrix metalloproteinases and tissue factor in vivo and in vitro. Circulation. 2001;103(2):276-283.

54. Cleland JG, McMurray JJ, Kjekshus J, et al; CORONA Study Group. Plasma concentration of amino-terminal pro-brain natriuretic peptide in chronic heart failure: prediction of cardiovascular events and interaction with the effects of rosuvastatin: a report from CORONA (Controlled Rosuvastatin Multinational Trial in Heart Failure). J Am Coll Cardiol. 2009;54(20):1850-1859.

55. Kang PM, Izumo S. Apoptosis and heart failure: A critical review of the literature. Circ Res. 2000;86(11):1107-1113.

56. Thunyakitpisal PD, Chaisuparat R. Simvastatin, an HMG-CoA reductase inhibitor, reduced the expression of matrix metalloproteinase-9 (Gelatinase B) in osteoblastic cells and HT1080 fibrosarcoma cells. Journal of Pharmacological Sciences. 2004;94(4):403-409.

57. Mitani H, Bandoh T, Ishikawa J, Kimura M, Totsuka T, Hayashi S. Inhibitory effects of fluvastatin, a new HMG-CoA reductase inhibitor, on the increase in vascular ACE activity in cholesterol-fed rabbits. $\mathrm{Br}$ J Pharmacol. 1996;119(6):1269-1275.
58. Luo JD, Zhang WW, Zhang GP, Guan JX, Chen X. Simvastatin inhibits cardiac hypertrophy and angiotensin-converting enzyme activity in rats with aortic stenosis. Clin Exp Pharmacol Physiol. 1999;26(11):903-908.

59. Takemoto M, Node K, Nakagami H, et al. Statins as antioxidant therapy for preventing cardiac myocyte hypertrophy. J Clin Invest. 2001; 108(10):1429-1437.

60. Shepherd J, Blauw GJ, Murphy MB, et al; PROSPER study group. PROspective Study of Pravastatin in the Elderly at Risk. Pravastatin in elderly individuals at risk of vascular disease (PROSPER): a randomised controlled trial. Lancet. 2002;360(9346):1623-1630.

61. Krum H, Ashton E, Reid C, et al. Double-Blind, randomized, placebocontrolled study of high-dose hmg coa reductase inhibitor therapy on ventricular remodeling, pro-inflammatory cytokines and neurohormonal parameters in patients with chronic systolic heart failure. J Card Fail. 2007;13(1):1-7.

62. Cannon CP, Braunwald E, McCabe CH, et al; Pravastatin or Atorvastatin Evaluation and Infection Therapy-Thrombolysis in Myocardial Infarction 22 Investigators. Intensive versus moderate lipid lowering with statins after acute coronary syndromes. $N$ Engl $J$ Med. 2004;350(15):1495-1504.

63. Sharma UC, Pokharel S, van Brakel TJ, et al. Galectin-3 marks activated macrophages in failure-prone hypertrophied hearts and contributes to cardiac dysfunction. Circulation. 2004;110(19):3121-3128.

64. van Kimmenade RR, Januzzi JL Jr, Ellinor PT, et al. Utility of aminoterminal pro-brain natriuretic peptide, galectin-3, and apelin for the evaluation of patients with acute heart failure. $\mathrm{J} \mathrm{Am} \mathrm{Coll} \mathrm{Cardiol.} \mathrm{2006;}$ 48(6):1217-1224.

65. Lok DJ, Van Der Meer P, de la Porte PW, et al. Prognostic value of galectin-3, a novel marker of fibrosis, in patients with chronic heart failure: data from the DEAL-HF study. Clin Res Cardiol. 2010; 99(5):323-328.

66. de Boer RA, Lok DJ, Jaarsma T, et al. Predictive value of plasma galectin-3 levels in heart failure with reduced and preserved ejection fraction. Ann Med. 2011;43(1):60-68.

67. Gullestad L, Ueland T, Kjekshus J, et al; CORONA Study Group. Galectin-3 predicts response to statin therapy in the Controlled Rosuvastatin Multinational Trial in Heart Failure (CORONA). Eur Heart J. 2012;33(18):2290-2296.

68. van der Harst P, Voors AA, van Gilst WH, van Veldhuisen DJ. Statins and autonomic function in chronic heart failure. Cardiovasc Drugs Ther. 2005;19(3):167-168.

69. Goldman S, Johnson G, Cohn JN, Cintron G, Smith R, Francis G. Mechanism of death in heart failure. The Vasodilator-Heart Failure Trials. The V-HeFT VA Cooperative Studies Group. Circulation. 1993;87(Suppl 6):VI24-VI31.

70. Muders F, Kromer EP, Griese DP, et al. Evaluation of plasma natriuretic peptides as markers for left ventricular dysfunction. Am Heart J. 1997; 134(3):442-449.

71. Ridker PM, Rifai N, Pfeffer MA, Sacks F, Braunwald E. Long-term effects of pravastatin on plasma concentration of C-reactive protein. The Cholesterol and Recurrent Events (CARE) Investigators. Circulation. 1999;100(3):230-235.

72. Oi S, Haneda T, Osaki J, et al. Lovastatin prevents angiotensin IIinduced cardiac hypertrophy in cultured neonatal rat heart cells. Eur $J$ Pharmacol. 1999;376(1-2):139-148.

73. Pliquett RU, Cornish KG, Peuler JD, Zucker IH. Simvastatin normalizes autonomic neural control in experimental heart failure. Circulation. 2003;107(19):2493-2498.

74. Masson S, Latini R, Anand IS, et al; Val-HeFT Investigators. Direct comparison of B-type natriuretic peptide (BNP) and amino-terminal proBNP in a large population of patients with chronic and symptomatic heart failure: the Valsartan Heart Failure (Val-HeFT) data. Clin Chem. 2006;52(8):1528-1538.

75. Omland T, Sabatine MS, Jablonski KA, et al; PEACE Investigators. Prognostic value of B-Type natriuretic peptides in patients with stable coronary artery disease: the PEACE Trial. J Am Coll Cardiol. 2007;50(3):205-214. 
76. Tulevski II, Groenink M, van Der Wall EE, et al. Increased brain and atrial natriuretic peptides in patients with chronic right ventricular pressure overload: correlation between plasma neurohormones and right ventricular dysfunction. Heart. 2001;86(1):27-30.

77. Krüger S, Graf J, Kunz D, Stickel T, Hanrath P, Janssens U. Brain natriuretic peptide levels predict functional capacity in patients with chronic heart failure. J Am Coll Cardiol. 2002;40(4):718-722.

78. McDonagh TA, Robb SD, Murdoch DR, et al. Biochemical detection of left-ventricular systolic dysfunction. Lancet. 1998; 351(9095):9-13.

79. Nakaya R, Uzui H, Shimizu H, et al. Pravastatin suppresses the increase in matrix metalloproteinase-2 levels after acute myocardial infarction. Int J Cardiol. 2005;105(1):67-73.

80. Hayashidani S, Tsutsui H, Shiomi T, et al. Fluvastatin, a 3-hydroxy-3methylglutaryl coenzyme a reductase inhibitor, attenuates left ventricular remodeling and failure after experimental myocardial infarction. Circulation. 2002;105(7):868-873.

81. Keidar S, Aviram M, Maor I, Oiknine J, Brook JG. Pravastatin inhibits cellular cholesterol synthesis and increases low density lipoprotein receptor activity in macrophages: in vitro and in vivo studies. Br J Clin Pharmacol. 1994;38(6):513-519.

82. Heart Protection Study Collaborative Group. MRC/BHF Heart Protection Study of cholesterol lowering with simvastatin in 20536 high-risk individuals: a randomised placebo-controlled trial. Lancet. 2002;360(9326):7-22.

83. Remme WJ. Overview of the relationship between ischemia and congestive heart failure. Clin Cardiol. 2000;23(7 Suppl 4):IV4-IV8.

84. Rosenson RS, Tangney CC. Antiatherothrombotic properties of statins: implications for cardiovascular event reduction. JAMA. 1998;279(20):1643-1650.

85. Kjekshus J, Pedersen TR, Olsson AG, Faergeman O, Pyörälä K. The effects of simvastatin on the incidence of heart failure in patients with coronary heart disease. J Card Fail. 1997;3(4):249-254.

86. Jackson G, Gibbs CR, Davies MK, Lip GY. ABC of heart failure. Pathophysiology. BMJ. 2000;320(7228):167-170.

87. Hanna IR, Heeke B, Bush H, et al. Lipid-lowering drug use is associated with reduced prevalence of atrial fibrillation in patients with left ventricular systolic dysfunction. Heart Rhythm. 2006;3(8):881-886.

88. Fauchier L, Pierre B, de Labriolle A, Grimard C, Zannad N, Babuty D. Antiarrhythmic effect of statin therapy and atrial fibrillation a meta-analysis of randomized controlled trials. J Am Coll Cardiol. 2008;51(8):828-835.

89. Vyas AK, Guo H, Moss AJ, et al; MADIT-II Research Group. Reduction in ventricular tachyarrhythmias with statins in the Multicenter Automatic Defibrillator Implantation Trial (MADIT)-II. J Am Coll Cardiol 2006;47(4):769-773.

90. Goldberger JJ, Subacius H, Schaechter A, et al; DEFINITE Investigators. Effects of statin therapy on arrhythmic events and survival in patients with nonischemic dilated cardiomyopathy. J Am Coll Cardiol. 2006;48(6):1228-1233.

91. Tamargo J, Caballero R, Gómez R, Núñez L, Vaquero M, Delpón E. Lipid-lowering therapy with statins, a new approach to antiarrhythmic therapy. Pharmacol Ther. 2007;114(1):107-126.

92. Adam O, Frost G, Custodis F, et al. Role of Rac1 GTPase activation in atrial fibrillation. J Am Coll Cardiol. 2007;50(4):359-367.

93. Rahimi K, Emberson J, McGale P, et al; PROSPER Executive. Effect of statins on atrial fibrillation: collaborative meta-analysis of published and unpublished evidence from randomised controlled trials. BMJ. 2011;342:d1250.

94. Rauchhaus M, Clark AL, Doehner W, et al. The relationship between cholesterol and survival in patients with chronic heart failure. J Am Coll Cardiol. 2003;42(11):1933-1940.

95. Treasure CB, Klein JL, Weintraub WS, et al. Beneficial effects of cholesterol-lowering therapy on the coronary endothelium in patients with coronary artery disease. $N$ Engl J Med. 1995;332(8):481-487.

96. Mortensen SA, Leth A, Agner E, Rohde M. Dose-related decrease of serum coenzyme Q10 during treatment with HMG-CoA reductase inhibitors. Mol Aspects Med. 1997;18 Suppl:S137-S144.
97. Moosmann B, Behl C. Selenoprotein synthesis and side-effects of statins. Lancet. 2004;363(9412):892-894.

98. Poehlman ET, Scheffers J, Gottlieb SS, Fisher ML, Vaitekevicius P.Increased resting metabolic rate in patients with congestive heart failure. Ann Intern Med. 1994;121(11):860-862.

99. Rundek T, Naini A, Sacco R, Coates K, DiMauro S. Atorvastatin decreases the coenzyme Q10 level in the blood of patients at risk for cardiovascular disease and stroke. Arch Neurol. 2004;61(6): 889-892.

100. Athyros VG, Mikhailidis DP, Papageorgiou AA, et al. Effect of atorvastatin on high density lipoprotein cholesterol and its relationship with coronary events: a subgroup analysis of the GREek Atorvastatin and Coronary-heart-disease Evaluation (GREACE) Study. Current medical research and opinion. May 2004;20(5):627-637.

101. Pedersen TR, Faergeman O, Kastelein JJ, et al; Incremental Decrease in End Points Through Aggressive Lipid Lowering (IDEAL) Study Group. High - dose atorvastatin vrs usual - dose simvastatin for secondary prevention after myocardial infarction: IDEAL study: a randomized-controlled trial. JAMA. 2005;294(19):2437-2445.

102. Khush KK, Waters DD, Bittner V, et al. Effect of high-dose atorvastatin on hospitalization for heart failure: subgroup analysis of the Treat to New Targets (TNT) study. Circulation. 2007;115(5):576-583.

103. Kubota T, Miyagishima M, Alvarez RJ, et al. Expression of proinflammatory cytokines in the failing human heart: comparison of recentonset and end-stage congestive heart failure. J Heart Lung Transplant. 2000;19(9):819-824.

104. Krum H, Latini R, Maggioni AP, et al. Statins and symptomatic chronic systolic heart failure: a post-hoc analysis of 5010 patients enrolled in Val-HeFT. Int J Cardiol. 2007;119(1):48-53.

105. Krum H, Bailey M, Meyer W, et al. Impact of statin therapy on mortality in CHF patients according to beta-blocker use: results of CIBIS II. Cardiology. 2007;108(1):28-34.

106. Anker SD, Clark AL, Winkler R, et al. Statin use and survival in patients with chronic heart failure: results from two observational studies with 5200 patients. Int J Cardiol. 2006;112(2):234-242.

107. Joynt KE, Gattis WA, Hasselblad V, et al. Effect of angiotensinconverting enzyme inhibitors, beta blockers, statins, and aspirin on $\mathrm{C}$-reactive protein levels in outpatients with heart failure. Am J Cardiol. 2004;93(6):783-785.

108. Go AS, Lee WY, Yang J, Lo JC, Gurwitz JH. Statin therapy and risks for death and hospitalization in chronic heart failure. JAMA. 2006; 296(17):2105-2111.

109. Foody JM, Shah R, Galusha D, Masoudi FA, Havranek EP, Krumholz HM. Statin and mortality among elderly patients hospitalized with heart failure. Circulation. 2006;113(8):1086-1092.

110. Hognestad A, Dickstein K, Myhre E, Snapinn S, Kjekshus J; OPTIMAAL Investigators. Effect of combined statin and beta-blocker treatment on one-year morbidity and mortality after acute myocardial infarction associated with heart failure. Am J Cardiol. 2004;93(5): 603-606.

111. Ray JG, Gong Y, Sykora K, Tu JV. Statin use and survival outcomes in elderly patients with heart failure. Arch Intern Med. 2005;165(1): 62-67.

112. Sola S, Mir MQS, Rajagopalan S, Helmy T, Tandon N, Khan BV. Statin therapy is associated with improved cardiovascular outcomes and levels of inflammatory markers in patients with heart failure. J Card Fail. 2005;11(8):607-612.

113. Thambidorai SK, Deshmukh AR, Walters RW, et al. Impact of statin use on heart failure mortality. Int J Cardiol. 2011;147(3): 438-443.

114. Maison P, Desamericq G, Hemery F, et al. Relationship between recommended chronic heart failure treatments and mortality over 8 years in real-world conditions: a pharmacoepidemiological study. Eur J Clin Pharmacol. 2013;69(4):901-908.

115. Gastelurrutia P, Lupón J, de Antonio M, et al. Statins in heart failure: the paradox between large randomized clinical trials and real life. Mayo Clin Proc. 2012;87(6):555-560. 
116. Vrtovec B, Okrajsek R, Golicnik A, et al. Atorvastatin therapy may reduce the incidence of sudden cardiac death in patients with advanced chronic heart failure. J Card Fail. 2008;14(2):140-144.

117. Wojnicz R, Wilczek K, Nowalany-Kozielska E, et al. Usefulness of atorvastatin in patients with heart failure due to inflammatory dilated cardiomyopathy and elevated cholesterol levels. Am J Cardiol. 2006;97(6):899-904

118. Xie RQ, Cui W, Liu F, Yang C, Pei WN, Lu JC. Statin therapy shortens QTc, QTed, and improves cardiac function in patients with chronic heart failure. Int J Cardiol. 2010;140(2):255-257.

119. Sola S, Mir MQ, Lerakis S, Tandon N, Khan BV. Atorvastatin improves left ventricular systolic function and serum markers of inflammation in nonischemic heart failure. J Am Coll Cardiol. 2006;47(2):332-337.

120. Yamada T, Node K, Mine T, et al. Long-term effect of atorvastatin on neurohumoral activation and cardiac function in patients with chronic heart failure: A prospective randomized controlled study. Am Heart J. 2007;153(6):1055. e1-1055. e8.

121. Node K, Fujita M, Kitakaze M, Hori M, Liao JK. Short-term statin therapy improves cardiac function and symptoms in patients with idiopathic dilated cardiomyopathy. Circulation. 2003;108(7):839-843.

122. Hamaad A, Sosin M, Lip GY, MacFadyen RJ. Short-term adjuvant atorvastatin improves frequency domain indices of heart rate variability in stable systolic heart failure. Cardiovasc Drugs Ther. 2005;19(3):183-187.

123. Bleske BE, Nicklas JM, Bard RL, et al. Neutral effect on markers of heart failure, inflammation, endothelial activation and function, and vagal tone after high-dose HMG-CoA reductase inhibition in nondiabetic patients with non-ischemic cardiomyopathy and average lowdensity lipoprotein level. J Am Coll Cardiol. 2006;47(2):338-341.

124. Laufs U, Wassmann S, Schackmann S, Heeschen C, Böhm M, Nickenig G. Beneficial effects of statins in patients with non-ischemic heart failure. Z Kardiol. 2004;93(2):103-108.

125. Tousoulis D, Andreou I, Tentolouris C, et al. Comparative effects of rosuvastatin and allopurinol on circulating levels of matrix metalloproteinases and tissue inhibitors of metalloproteinases in patients with chronic heart failure. Int J Cardiol. 2010;145(3):438-443.

126. Erbs S, Beck EB, Linke A, et al. High-dose rosuvastatin in chronic heart failure promotes vasculogenesis, corrects endothelial function, and improves cardiac remodeling - results from a randomized, double-blind, and placebo-controlled study. Int J Cardiol. 2011; 146(1):56-63.

127. Tsutamoto T, Sakai H, Ibe K, et al. Effect of atorvastatin vs rosuvastatin on cardiac sympathetic nerve activity in non-diabetic patients with dilated cardiomyopathy. Circ J. 2011;75(9):2160-2166.

128. Andreou I, Tousoulis D, Miliou A, et al. Effects of rosuvastatin on myeloperoxidase levels in patients with chronic heart failure: a randomized placebo-controlled study. Atherosclerosis. 2010;210(1): 194-198.

129. Bielecka-Dabrowa A, Goch JH, Mikhailidis DP, Rysz J, Maciejewski M, Banach M. The influence of atorvastatin on parameters of inflammation and function of the left ventricle in patients with dilated cardiomyopathy. Med Sci Monit. 2009;15(12):MS12-MS23.

130. Tousoulis D, Antoniades C, Bosinakou E, et al. Effects of atorvastatin on reactive hyperemia and inflammatory process in patients with congestive heart failure. Atherosclerosis. 2005;178(2):359-363.

131. Horwich TB, Middlekauff HR, Maclellan WR, Fonarow GC. Statins do not significantly affect muscle sympathetic nerve activity in humans with nonischemic heart failure: a double-blind placebo-controlled trial. $J$ Card Fail. 2011;17(11):879-886.

132. Zhang S, Zhang L, Sun A, Jiang H, Qian J, Ge J. Efficacy of statin therapy in chronic systolic cardiac insufficiency: a meta-analysis. Eur J Intern Med. 2011;22(5):478-484.

133. Lipinski MJ, Cauthen CA, Biondi-Zoccai GG, et al. Meta-analysis of randomized controlled trials of statins versus placebo in patients with heart failure. Am J Cardiol. 2009;104(12):1708-1716.
134. Emberson JR, Ng LL, Armitage J, Bowman L, Parish S, Collins R; Heart Protection Study Collaborative Group. N-terminal Pro-B-type natriuretic peptide, vascular disease risk, and cholesterol reduction among 20,536 patients in the MRC/BHF heart protection study. $J$ Am Coll Cardiol. 2007;49(3):311-319.

135. Ochiai ME, Barretto AC, Oliveira MT Jr, Munhoz RT, Morgado PC, Ramires JA. Uric acid renal excretion and renal insufficiency in decompensated severe heart failure. Eur J Heart Fail. 2005;7(4): 468-474.

136. Rinfret S, Behlouli H, Eisenberg MJ, Humphries K, Tu JV, Pilote L. Class effects of statins in elderly patients with congestive heart failure: a population-based analysis. Am Heart J. 2008;155(2):316-323.

137. Juncos LI, Juncos LA, García NH. The antihypertensive actions of statins: modulation by salt intake. Am J Hypertens. 2012;25(11): 1140-1148.

138. Pelat M, Balligand JL. Statins and hypertension. Semin Vasc Med. 2004;4(4):367-375.

139. Leyva F, Anker S, Swan JW, et al. Serum uric acid as an index of impaired oxidative metabolism in chronic heart failure. Eur Heart J. 1997;18(5):858-865.

140. Anker SD, Doehner W, Rauchhaus M, et al. Uric acid and survival in chronic heart failure: validation and application in metabolic, functional, and hemodynamic staging. Circulation. 2003;107(15):1991-1997.

141. Cengel A, Türkoğlu S, Turfan M, Boyaci B. Serum uric acid levels as a predictor of in-hospital death in patients hospitalized for decompensated heart failure. Acta Cardiol. 2005;60(5):489-492.

142. Hare JM, Johnson RJ. Uric acid predicts clinical outcomes in heart failure: insights regarding the role of xanthine oxidase and uric acid in disease pathophysiology. Circulation. 2003;107(15):1951-1953.

143. Milionis HJ, Kakafika AI, Tsouli SG, et al. Effects of statin treatment on uric acid homeostasis in patients with primary hyperlipidemia. Am Heart J. 2004;148(4):635-640.

144. Athyros VG, Elisaf M, Papageorgiou AA, et al; GREACE Study Collaborative Group. Effect of statins versus untreated dyslipidemia on serum uric acid levels in patients with coronary heart disease: a subgroup analysis of the GREek Atorvastatin and Coronaryheart-disease Evaluation (GREACE) study. Am J Kidney Dis. 2004;43(4):589-599.

145. Ljungman S, Laragh JH, Cody RJ. Role of the kidney in congestive heart failure. Relationship of cardiac index to kidney function. Drugs. 1990;39 Suppl 4:10-21; discussion 22-24.146.

146. Elisaf M, Mikhailidis DP. Statins and renal function. Angiology. 2002;53(5):493-502.

147. Nagarajan V, Tang WH. Management of comorbid conditions in heart failure: a review. Med Clin North Am. 2012;96(5):975-985.

148. De Blois J, Simard S, Atar D, Agewall S; Norwegian Heart Failure Registry. COPD predicts mortality in HF: the Norwegian Heart Failure Registry. J Card Fail. 2010;16(3):225-229.

149. Salpeter SR, Ormiston TM, Salpeter EE. Cardiovascular effects of beta-agonists in patients with asthma and COPD: a meta-analysis. Chest. 2004;125(6):2309-2321.

150. Roche N. Where current pharmacological therapies fall short in COPD: symptom control is not enough. Eur Respir Rev. 2007;16(105): 98-104.

151. Janda S, Park K, FitzGerald JM, Etminan M, Swiston J. Statins in COPD: a systematic review. Chest. 2009;136(3):734-743.

152. Dobler CC, Wong KK, Marks GB. Associations between statins and COPD: a systematic review. BMC Pulm Med. 2009;9:32.

153. Bonsu KO, Kadirvelu A, Reidpath DD. Lipophilic versus hydrophilic statin therapy for heart failure: a protocol for an adjusted indirect comparison meta-analysis. Systematic reviews. 2013;2:22. 


\section{Publish your work in this journal}

Vascular Health and Risk Management is an international, peerreviewed journal of therapeutics and risk management, focusing on concise rapid reporting of clinical studies on the processes involved in the maintenance of vascular health; the monitoring, prevention and treatment of vascular disease and its sequelae; and the involvement of metabolic disorders, particularly diabetes. This journal is indexed on PubMed Central and MedLine. The manuscript management system is completely online and includes a very quick and fair peer-review system, which is all easy to use. Visit http://www.dovepress.com/ testimonials.php to read real quotes from published authors.

Submit your manuscript here: http://www.dovepress.com/vascular-health-and-risk-management-journal 